\title{
Gait variables comparison between pregnant women with and without lumbopelvic pain
}

\author{
Comparação entre variáveis da marcha entre grávidas com e sem dor lombopélvica
}

Vanessa Patrícia Soares de Sousa', Vitória Jéssica Teixeira Dantas², Silvia Oliveira Ribeiro Lira', Alethéa Cury², Caroline N. A. Medeiros $^{2}$, Elizabel de Souza Ramalho Viana ${ }^{2}$

DOI 10.5935/2595-0118.20180042

\section{ABSTRACT}

BACKGROUND AND OBJECTIVES: The various gestational adaptations may lead to changes in the gait pattern. Also, the lumbopelvic pain in this period can impact the gait dynamics. The objective of this study was to compare gait variables between pregnant women with and without lumbopelvic pain, according to the gestational trimesters, and to compare the outcome variables between the second and third gestational trimesters.

METHODS: Analytical and cross-sectional study with 277 pregnant women. They were divided into two groups, considering the gestational trimester as a grouping factor. Subsequently, the two groups were subdivided considering the absence or presence of lumbopelvic pain. All participants were submitted to the evaluation protocol: identification form, visual analog scale, and gait assessment using the Balance Master System ${ }^{\circledR}$.

RESULTS: The chronological age averages of the second and third-trimester groups were, respectively, 29.9 \pm 4.6 and 29.7 \pm 3.7 years. When comparing gait variables between pregnant women with and without lumbopelvic pain, a statistically significant difference was observed only for the gait velocity $(p=0.04)$ in the third-trimester group.

CONCLUSION: It is suggested that women in the third trimester with complaints of lumbopelvic pain have reduced gait velocity when compared to those without pain.

Keywords: Gait, Low back pain, Pregnancy.
1. Universidade Federal do Rio Grande do Norte, Faculdade de Ciências da Saúde do Trairi, Departamento de Fisioterapia, Santa Cruz, RN, Brasil.

2. Universidade Federal do Rio Grande do Norte, Departamento de Fisioterapia, Natal, $\mathrm{RN}$, Brasil.

Submitted in March 20, 2018.

Accepted for publication on June 27, 2018.

Conflict of interests: none - sponsoring sources: none.

Correspondence to:

R. Teodorico Bezerra, 2-122, Santa Cruz

59200-000 Santa Cruz, RN, Brasil.

E-mail: elizabelviana@gmail.com

(C) Sociedade Brasileira para o Estudo da Dor

\section{RESUMO}

JUSTIFICATIVA E OBJETIVOS: As diversas adaptaçôes decorrentes da gestação podem levar a modificaçốes no padrão da marcha. A queixa de dor lombopélvica nesse período pode repercutir na dinâmica da marcha. Assim, o objetivo deste estudo foi comparar as variáveis da marcha entre gestantes com e sem dor lombopélvica, respeitando os trimestres gestacionais, e comparar as variáveis-desfecho entre o segundo e o terceiro trimestre gestacionais.

MÉTODOS: Estudo do tipo analítico e transversal com 277 gestantes alocadas em dois grupos, considerando o trimestre gestacional como fator de agrupamento. Posteriormente, os dois grupos foram subdivididos considerando a ausência ou presença de dor lombopélvica. Todas as participantes foram submetidas ao protocolo de avaliação: preenchimento de ficha de identificação, escala analógica visual e avaliação da marcha por meio do Balance Master System ${ }^{\oplus}$.

RESULTADOS: As médias da idade cronológica para o grupo do segundo e terceiro trimestres foram, respectivamente, entre $29,9 \pm 4,6$ e $29,7 \pm 3,7$ anos. Ao comparar as variáveis da marcha entre gestantes com e sem dor lombopélvica foi observada diferença estatisticamente significativa, apenas para a velocidade da marcha $(\mathrm{p}=0,04)$, no grupo do terceiro trimestre.

CONCLUSÃO: Sugere-se que mulheres no terceiro trimestre com queixas de dor lombopélvica apresentam reduçấo da velocidade da marcha, quando comparadas àquelas sem dor.

Descritores: Dor lombopélvica, Gravidez, Marcha.

\section{INTRODUCTION}

Pregnancy is a physiological process in which several changes occur in the woman's body that can lead to changes in the gait pattern. These changes include: ligament laxity, changes in the center of gravity (CG), decreased neuromuscular control, anthropometric alterations in the size of the support base and the width of the feet, deviations of ground reaction forces (GRF) and propulsion force ${ }^{1,2}$.

During pregnancy, women often complain about lumbopelvic pain (LPP) $)^{3,4}$. LPP usually increases throughout pregnancy, reaching a peak of greater severity in the third trimester ${ }^{4}$. Increased abdominal volume observed during this period may cause a decrease in the range of motion of the torso, and it may affect their gait dynamics ${ }^{3}$. 
Gait is an activity of daily life, being one of the main abilities of the human being. Even though it is a natural gesture, it is believed that different patterns in this ability occur throughout the gestation process 5 . Previous studies analyzing gait changes during pregnancy report that there is a decrease in gait length, increased step width, changes in torso movement and reduced self-selected walking speed ${ }^{4}$ during this period. There is also an increase in the duration of the stance phase, while the duration of the swing phase remains virtually unchanged ${ }^{6}$.

Previous studies have suggested that pregnant women with lumbopelvic pain have impairments in performing gait due to changes in coordinating pelvis and torso rotation ${ }^{5}$. In addition, musculoskeletal discomfort in this period may be associated with overloads occurring as a consequence of secondary gait deviations, which try to correct weight gains and weight distribution throughout the body 5 . These factors make it difficult to analyze the characteristics of gait during pregnancy, and it is necessary that its evaluation respects the gestational trimester.

However, there are still few studies that analyze the influence of LPP on gait variables during gestation. Thus, this article has the main objective to compare the gait variables between pregnant women with and without LPP, respecting the gestational trimesters which the volunteers are in. Secondly, we aimed to compare the outcome variables between the second and third gestational trimesters.

\section{METHODS}

This study is characterized as analytical and cross-sectional research.

The research was developed in the Physiotherapy Department of the Federal University of Rio Grande do Norte, in the Laboratory of Analysis of Neuromuscular Performance (LAPERN), from December 2014 to December 2015.

The sample of 277 pregnant women was recruited from a population of 338 pregnant women attending the Multiprofessional Course for Pregnant Women, sampled by convenience. For the initial analyzes, the sample was divided into two groups, considering the pregnant women who were in the second and third trimesters as a grouping factor. These two groups were subsequently subdivided, regarding the absence or presence of lumbopelvic pain, as shown in the flowchart (Figure 1).

The inclusion criteria for the sample selection were: (1) women in the second or third gestational trimesters; (2) enrolled and participating in the Multiprofessional Course for Pregnant Women; and (3) with low-risk pregnancies. Those who: (1) did not complete the evaluation protocol; or (2) wished to drop out of the study were excluded from the research.

Clinical, obstetric and gestational-related information was collected through an evaluation form designed and structured by

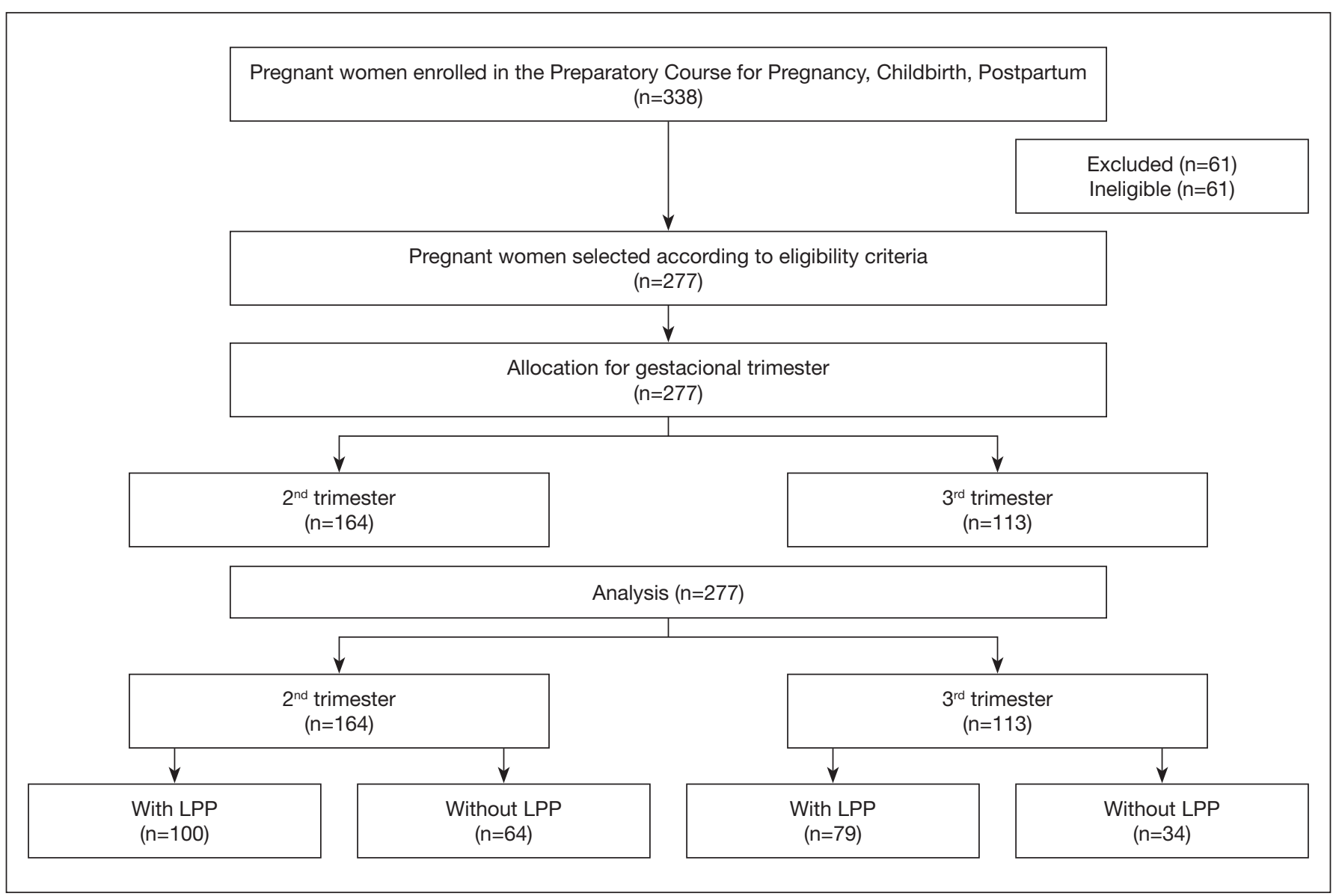

Figure 1. Study distribution flowchart

LPP = lumbopelvic pain. 
the responsible researchers. After this procedure, volunteers were questioned about the presence or absence of LPP. If affirmative, the pregnant woman informed the researcher about the intensity of pain according to the visual analog scale (VAS). The VAS is an instrument graduated from zero to 10 , in which zero represents the absence of pain, and 10 the maximum amount of tolerable pain. The pain intensity is divided into categories, in which: 1 to 2 , the intensity is considered mild; 3 to 7 is moderate; 8 to 9 is intense, and 10 is unbearable. This instrument has been used for the evaluation of pain intensity in populations of pregnant women ${ }^{7,8}$. The Balance Master System ${ }^{\circledR}$ (NeuroCom, Clackamas, USA) was used for evaluating gait. This equipment consists of a system that uses a force platform with four transducers which measure the vertical reaction forces exerted by the individual's feet, the CG position and quantitative measures of static and dynamic balance performance?. The analysis of the gait variables was performed using the Walk Across (WA) test.

During execution of the WA test, the participants had their gait evaluated into four different variables, obtaining measurements for each of: (1) step width (SW) in centimeters; (2) step length (SL) in centimeters; (3) speed of progression (SPEED), in centimeters per second; and (4) symmetry of step length (SSL) in percentage (9). Each participant performed the test 3 times, and an average of the obtained values was implemented for data analysis. In all the situations, the volunteer was instructed to walk at free speed. The study was approved by the Human Research Ethics Committee of the Federal University of Rio Grande do Norte under protocol number 719.939 and registered in the Brazilian Registry of Clinical Trials under the Registry number RBR-4j35g5.
All the volunteers signed the Free and Informed Consent Form (FICF) in accordance with Resolution 466/12 of the National Health Council.

\section{Statistical analysis}

The Shapiro Wilk test was used to verify the normality of the quantitative variables. For the sample characterization, a descriptive analysis was performed regarding sociodemographic, obstetric and anthropometric data, lifestyle and lumbopelvic pain. This analysis presented the average and the standard deviation, as well as the absolute and relative frequencies, depending on the type of variable (categorical and quantitative).

The Mann-Whitney test was used to compare the gait variables between the formed groups considering the gestational trimester and the presence or absence of lumbopelvic pain. The statistical significance considered was $\mathrm{p}<0.05$. The calculation of the sample size was done through openepi.com site. A power of $80 \%, 95 \%$ confidence interval and the following means for the oscillation velocity were considered: group with pain, $14^{\circ} / \mathrm{sec} \pm 4$ and group without pain, $10^{\circ} / \mathrm{sec} \pm 5$. The sample per group was 21 . Therefore, the sample expected for the study was 88 pregnant women.

\section{RESULTS}

The total sample for this study was 277 pregnant women. The average for the chronological age for the second and third-trimester groups was $29.9 \pm 4.6$ and $29.7 \pm 3.7$ years, respectively. The other data represent sociodemographic, obstetric and anthropometric data, life habits and data regarding subjective pain (Table 1).

Table 1. Sociodemographic, obstetrical and anthropometric characteristics of pregnant women participating in the study ( $\mathrm{n}=277$ )

\begin{tabular}{|c|c|c|c|}
\hline Variables & $\begin{array}{c}2 \mathrm{~T} \\
(\mathrm{n}=164)\end{array}$ & $\begin{array}{c}3 \mathrm{~T} \\
(\mathrm{n}=113)\end{array}$ & $\mathrm{p}$-value \\
\hline $\begin{array}{l}\text { Sociodemographic data } \\
\text { Age (years) (Mean } \pm \text { SD) }\end{array}$ & $29.90 \pm 4.67$ & $29.77 \pm 3.72$ & 0.80 \\
\hline Education level (years) (Mean \pm SD) & $16.34 \pm 3.25$ & $16.62 \pm 3.49$ & 0.54 \\
\hline $\begin{array}{l}\text { Marital status ( } \% \text { and } n) \\
\text { Have a partner } \\
\text { Does not have a partner }\end{array}$ & $\begin{array}{l}93.9(154) \\
6.1(10)\end{array}$ & $\begin{array}{l}92.9(105) \\
7.1(8)\end{array}$ & \\
\hline $\begin{array}{l}\text { Obstetrical data (Mean } \pm \text { SD) } \\
\text { GA (weeks) }\end{array}$ & $20.79 \pm 3.51$ & $30.05 \pm 2.31$ & $0.001^{*}$ \\
\hline $\begin{array}{l}\text { Parity (\% and } n) \\
\text { Nulliparous } \\
\text { Multiparous }\end{array}$ & $\begin{array}{l}90.2(148) \\
9.8(16)\end{array}$ & $\begin{array}{l}95.6(108) \\
\quad 4.4(5)\end{array}$ & \\
\hline Anthropometric data and life habits & & & \\
\hline Weight $(\mathrm{kg})$ & $66.21 \pm 10.41$ & $71.30 \pm 10.25$ & $0.001^{*}$ \\
\hline Height (m) & $1.62 \pm 0.06$ & $1.62 \pm 0.06$ & 0.81 \\
\hline $\begin{array}{l}\text { Body mass index } \\
\text { Weight gain }(\mathrm{kg})\end{array}$ & $\begin{array}{l}24.93 \pm 4.0 \\
5.97 \pm 4.20\end{array}$ & $\begin{array}{c}27.01 \pm 3.66 \\
5.86 \pm 3.63\end{array}$ & $\begin{array}{c}0.001^{*} \\
0.82\end{array}$ \\
\hline $\begin{array}{l}\text { Physical activity (\% and } \mathrm{n} \text { ) } \\
\text { Active } \\
\text { Sedentary }\end{array}$ & $\begin{array}{l}36(59) \\
64(105)\end{array}$ & $\begin{array}{l}46 \%(55) \\
54 \%(61)\end{array}$ & \\
\hline Subjective data from LPP $($ Mean $\pm S$ & & & \\
\hline VAS & $3.37 \pm 2.9$ & $3.72 \pm 2.8$ & \\
\hline
\end{tabular}


Table 2. Comparison of the variables of gait among pregnant women with and without lumbopelvic pain, considering the gestational trimesters

\begin{tabular}{|c|c|c|c|c|c|c|}
\hline \multirow[t]{3}{*}{ Variables } & \multirow{2}{*}{\multicolumn{3}{|c|}{$\begin{array}{c}2^{\text {nd }} \text { Trimester } \\
\text { Lumbopelvic Pain }\end{array}$}} & \multirow{2}{*}{\multicolumn{3}{|c|}{$\begin{array}{c}3^{\text {rd }} \text { Trimester } \\
\text { Lumbopelvic Pain }\end{array}$}} \\
\hline & & & & & & \\
\hline & $\begin{array}{c}\text { No. } \\
(n=64)\end{array}$ & $\begin{array}{c}\text { Yes } \\
(n=100)\end{array}$ & $\mathrm{p}$-value & $\begin{array}{l}\text { No. } \\
(n=34)\end{array}$ & $\begin{array}{c}\text { Yes } \\
(n=79)\end{array}$ & $p$-value \\
\hline SW & $\begin{array}{c}14.20 \\
(12.52-15.92)\end{array}$ & $\begin{array}{c}14.70 \\
(12.07-16.17)\end{array}$ & 0.74 & $\begin{array}{c}15 \\
(12.40-16.72)\end{array}$ & $\begin{array}{c}14.90 \\
(12,60-17,20)\end{array}$ & 0.80 \\
\hline ASL & $\begin{array}{c}56.70 \\
(50.65-61.30)\end{array}$ & $\begin{array}{c}54.80 \\
(48.72-59.97)\end{array}$ & 0.10 & $\begin{array}{c}55.05 \\
(48.12-64.82)\end{array}$ & $\begin{array}{c}55.20 \\
(48.80-59.60)\end{array}$ & 0.64 \\
\hline SCP & $\begin{array}{c}10.50 \\
(5.00-22.75)\end{array}$ & $\begin{array}{c}12 \\
(6.00-21.50)\end{array}$ & 0.49 & $\begin{array}{c}8 \\
(3.00-18.25)\end{array}$ & $\begin{array}{c}12 \\
(5.00-22.00)\end{array}$ & 0.14 \\
\hline
\end{tabular}

The variables are expressed as median and interquartile ranges. SW = step width (in $\mathrm{cm}$ ); $\mathrm{ASL}=$ average step length (in $\mathrm{cm}$ ); $\mathrm{SSL}=\mathrm{speed} \mathrm{step} \mathrm{length} \mathrm{(in} \mathrm{cm} / \mathrm{s}$ ); $\mathrm{SCP}$ = step length symmetry (in \%); *statistically significant differences $(<0.05)$.

Table 3. Comparative analysis of gait variables between women in the second and third gestational trimesters

\begin{tabular}{lccc}
\hline Variables & $\begin{array}{c}2 \mathrm{~T} \\
(\mathrm{n}=164)\end{array}$ & $\begin{array}{c}3 T \\
(\mathrm{n}=113)\end{array}$ & $\mathrm{p}$-value \\
\hline SW & 14.50 & 15.00 & 0.05 \\
& $(12.32-16.10)$ & $(12.55-17.00)$ & \\
ASL & 55.30 & 55.20 & 0.76 \\
& $(49.60-60.17)$ & $(48.75-60.40)$ & \\
SSL & 69.35 & 69.10 & 0.56 \\
& $(61.12-78.07)$ & $(60.85-76.15)$ & \\
SCP & 11.50 & 11.00 & 0.46 \\
& $(5.00-22.00)$ & $(4.00-21.00)$ & \\
\hline
\end{tabular}

The variables are expressed as median and interquartile ranges. SW = step width (in $\mathrm{cm}$ ); $\mathrm{ASL}=$ average step length (in $\mathrm{cm}$ ); $\mathrm{SSL}=$ speed step length (in $\mathrm{cm} / \mathrm{s}$ ); SCP = step length symmetry (in \%); $2 \mathrm{~T}=2^{\text {nd }}$ trimester; $3 \mathrm{~T}=3^{\text {rd }}$ trimester.

\section{Gait and lumbopelvic pain}

A statistically significant difference was only observed for gait velocity $(\mathrm{p}=0.04)$ in the third-trimester group when comparing gait variables between pregnant women with and without lumbopelvic pain according to the subjective pain assessment (Table 2).

\section{Gait and gestational trimester}

No significant differences $(\mathrm{p}<0.05)$ were found between the gait variables comparing pregnant women in the second and third trimesters. The results of this analysis are shown in table 3.

\section{DISCUSSION}

The objectives of this study were comparing gait variables between pregnant women with and without LPP and between the second and third trimesters. The main results show that there were no differences when comparing both groups by trimester. However, in relation to gait, pregnant women in the third trimester with LPP presented lower gait velocity when compared to pregnant women in the third-trimester without pain.

LPP is considered one of the main syndromes of the gestational period, affecting more than a third of pregnant women, especially in the third trimester of the gestational period ${ }^{10,11}$.

Previous studies have suggested that the gait pattern is modulated by the presence and intensity of pain, especially when it is lo- cated in the lumbar region, pelvic girdle and lower limbs ${ }^{12}$. Pelvic pain may lead to gait damage due to coordination problems in pelvic and torso rotation ${ }^{10,13,14}$.

No differences were found in gait variables for the group of pregnant women in the second trimester in the present study. However, pregnant women in the third trimester with LPP presented reduced gait velocity when compared to those without pain. This result was similar to that described by Wu et al. ${ }^{14}$ and Wu et al. ${ }^{13}$, who observed that pregnant women with low back pain had an average gait velocity lower than those who did not report pain ${ }^{13,14}$. The authors attributed this finding to the greater synchronization of the pelvic and thoracic rotations, reflecting in a smaller dissociation between these body regions ${ }^{14}$.

A study carried out by Yoo, Shin and Song ${ }^{4}$ suggests that gait velocity is reduced in pregnant women in the third trimester as a result of pain and the increased lumbar spine curvature. Moreover, this reduction is associated with the fact that pregnant women walk more carefully in order to minimize the risk of falls. The reduced gait velocity in women with pain complaints may be related to the overload in the muscular groups involved in the gait phases ${ }^{15}$. Pain is the result of a complex interaction between the signaling and modulation systems of higher centers, associated with individual perception ${ }^{16,17}$. Thus, it is suggested that the perception of pain in the group of pregnant women in the third trimester is more accentuated by the presence of factors such as fatigue, tiredness and edema (most common at the end of pregnancy), which may be mainly reflected in the gait velocity ${ }^{18}$.

No statistically significant difference was observed between groups comparing gait variables among women in the second and third gestational trimesters. Different results were found by Bertuit, Feipel and Rooze ${ }^{19}$, who compared space-time gait variables among pregnant, postpartum and non-pregnant women. By analyzing the group of pregnant women, the authors observed a decrease in gait velocity, step length, and cadence, in addition to increased step width among women in the third trimester compared to those in the second gestational trimester ${ }^{19}$. In analyzing the characteristics of lumbopelvic pain, gait and postural balance among pregnant women in the second and third trimester, Yoo, Shin and Song ${ }^{4}$ found that women in the third trimester had lower gait velocity and cadence compared 
to those in the second trimester. On the other hand, Branco, Santos-Rocha and Vieira ${ }^{20}$ suggest that there is a decrease in the length and increase in step width throughout pregnancy.

Gottschall, Sheedan and Downs ${ }^{21}$ compared spatiotemporal variables and muscle activation pattern among women in the second and third gestational trimesters and found that those in the third trimester presented lower gait velocity, more time in the support phase and increased step width when compared to those in the second trimester.

According to literature data, changes in gait spatiotemporal and angular variables may be related to weight gain during pregnan$\mathrm{cy}^{22,23}$, which mainly occurs in the third trimester. During this period, women gain between 11 and $16 \mathrm{~kg}^{24,25}$, which influences the maternal shape, size, and inertia ${ }^{26}$. Therefore, we suggest that the characteristic weight gain in pregnancy would affect the hip, knee and ankle joints through gravitational and acceleration factors. This fact would require an adaptation in the inter-segmental moments to fit the shape and inertia of the lower trunk and generate adjustments, both in posture and in gait during gestation ${ }^{5}$.

However, no differences in weight gain were observed in this study when comparing the second and third trimesters. For the sample studied, the mean weight gain was approximately $6 \mathrm{~kg}$. Thus, we suggest that the absence of statistical difference for gait variables when comparing both groups can be justified by a smaller value in weight gain. We also suggest that pregnant women adapt their gait pattern to maximize stability and control mid-lateral movements 5 .

\section{CONCLUSION}

The results of this study suggest that women in the third trimester with complaints of lumbopelvic pain present reduced gait velocity when compared to those without LPP. Additionally, we found that the gait pattern is similar among pregnant women in the second and third trimesters.

\section{ACKNOWLEDGMENTS}

Thanks to Coordenação de Aperfeiçoamento de Pessoal de Nível Superior (CAPES).

\section{REFERENCES}

1. Ribeiro SO, Sousa VP, Viana ES. Influence of virtual reality on postural balance and quality of life of pregnant women: controlled clinical trial randomized. Fisioter Mov. 2017;30(Suppl 1):111-20.
2. Aguiar L, Andrade C, Branco M, Santos-Rocha R, Vieira F, Veloso A. Global optimization method applied to the kinematics of gait in pregnant women. J Mech Med Biol. 2016;16(6): 1650084.

3. Sawa R, Doi T, Asai T, Watanabe K, Taniguchi T, Ono R. Differences in trunk contro between early and late pregnancy during gait. Gait Posture. 2015;42(4):455-9.

4. Yoo H, Shin D, Song C. Changes in the spinal curvature, degree of pain, balance ability, and gait ability according to pregnancy period in pregnant and nonpregnant women. J Phys Ther Sci. 2015;27(1):279-84.

5. Mann L, Kleinpaul JF, Mota CB, Santos SG. Alteraçôes biomecânicas durante o período gestacional: uma revisão. Motriz. 2010;16(3):730-41.

6. Błaszczyk JW, Opala-Berdzik A, Plewa M. Adaptive changes in spatiotemporal gait characteristics in women during pregnancy. Gait Posture. 2015;43:160-4.

7. Martins RF, Silva JL. [Back pain is a major problem for many pregnant women]. Rev Assoc Med Bras. 2005;51(3):144-7. Portuguese.

8. Martins RF, Pinto e Silva JL. Tratamento da lombalgia e dor pélvica posterior na gestação por um método de exercícios. Rev Bras Ginecol Obstet. 2005;27(5):275-82

9. NEUROCOM. NeuroCom Test Protocols. http://balanceandmobility.com/products/ neurocom-test-protocols/. 2015.

10. Wu W, Meijer OG, Lamoth CJ, Uegaki K, van Dieën JH, Wuisman PI, et al. Gait coordination in pregnancy: transverse pelvic and thoracic rotations and their relative phase. Clin Biomech (Bristol, Avon). 2004;19(5):480-8.

11. Mann L, Kleinpaul JF, Teixeira CS, Konopka CK. Dor lombo-pélvica e exercício físico durante a gestação. Fisioter Mov. 2008;21(2):99-105.

12. Arendt-Nielsen L, Graven-Nielsen T, Svarrer H, Svensson P. The influence of low back pain on muscle activity and coordination during gait: a clinical and experimental study. Pain. 1996;64(2):231-40.

13. Wu WH, Meijer OG, Bruijn SM, Hu H, van Dieën JH, Lamoth CJ, et al. Gait in Pregnancy-related Pelvic girdle Pain: amplitudes, timing, and coordination of horizontal trunk rotations. Eur Spine J. 2008;17(9):1160-9.

14. Wu W, Meijer OG, Jutte PC, Uegaki K, Lamoth CJ, Sander de Wolf G, et al. Gait in patients with pregnancy-related pain in the pelvis: an emphasis on the coordination of transverse pelvic and thoracic rotations. Clin Biomech. 2002;17(9-10):678-86.

15. Nakao H, Yoshikawa T, Mimura T, Hara T, Nishimoto K, Fujimoto S. Influence of lower-extremity muscle force, muscle mass and asymmetry in knee extension force on gait ability in community-dwelling elderly women. J Phys Ther Sci. 2006;18(1):73-9.

16. de Sousa VP, Ribeiro SO, de Aquino CM, Viana ES. Quality of sleep in pregnant woman with low back pain. Fisioter Mov. 2015;28(2):319-26.

17. Wasan AD, Anderson NK, Giddon DB. Differences in pain, psychological symptoms, and gender distribution among patients with left vs. right-sided chronic spinal pain. Pain Med. 2010;11(9):1373-80.

18. Mogren IM. BMI, pain and hyper-mobility are determinants of long-term outcome for women with low back pain and pelvic pain during pregnancy. Eur Spine J. 2006;15(7):1093-102.

19. Bertuit J, Feipel V, Rooze M. Temporal and spatial parameters of gait during pregnancy. Acta Bioeng Biomech. 2015;17(2):93-101.

20. Branco M, Santos-Rocha R, Vieira F. Biomechanics of gait during pregnancy. Sci World J. 2014;2014:527940.

21. Gottschall JS, Sheehan RC, Downs DS. Pregnant women exaggerate cautious gait patterns during the transition between level and hill surfaces. J Electromyogr Kinesiol. 2013;23(5):1237-42.

22. Albino MA, Moccellin AS, Firmento Bda D, Driusso P. [Gait force propulsion modifications during pregnancy: effects of changes in feet's dimensions]. Rev Bras Ginecol Obstet. 2011;33(7):164-9. Portuguese.

23. Foti T, Davids JR, Bagley A. A biomechanical analysis of gait during pregnancy. J Bone Joint Surg Am. 2000;82(5):625-33.

24. Butler EE, Colón I, Druzin ML, Rose J. Postural equilibrium during pregnancy: decreased stability with an increased reliance on visual cues. Am J Obstet Gynecol. 2006;195(4):1104-8.

25. Ersal T, McCrory J, Sienko KH. Theoretical and experimental indicators of falls during pregnancy as assessed by postural perturbations. Gait Posture. 2014;39(1):218-23.

26. Lou SZ, Chou YL, Chou PH, Lin CJ, Chen UC, Su FC. Sit-to-stand at different periods of pregnancy. Clin Biomech. 2001;16(3):194-8. 